\title{
Diagenetic Effect on Ba isotope composition of barites in from the Tarim Basin, NW China
}

\author{
Lan-Lan Tian ${ }^{\text {a }}$, Xi-Qiang Zhou ${ }^{\mathrm{b}}$, and Fang \\ Huang*a \\ a School of Earth and Space Sciences, USTC, Hefei, \\ Anhui, 230026, China \\ ${ }^{\mathrm{b}}$ Key Lab of Petroleum Resources Research, Institute \\ of Geology and Geophysics, Chinese Academy of \\ Sciences, Beijing 100029, China
}

Because of the stable chemical properties, sedimentary barites can record the primary productivity of paleo-oceans. Recently, barite $\mathrm{Ba}$ isotopes provide a novel method to explore the biogeochemistry of $\mathrm{Ba}$ in the ocean and to improve its applicability as a proxy for environmental studies. However, the poor preservation of barite under the sulfate-deficient anoxic conditions complicates the implications for a paleoceanographic record [1]. Therefore, it is important to understand the effect of diagenesis on $\mathrm{Ba}$ isotope compositions of barite. In order to constrain the $\mathrm{Ba}$ isotopic behaviour in anoxic environment, here we measure $\mathrm{Ba}$ isotopes of diagenetic barites which deposit in the black shale intervals of the Lower Cambrian Yurtus Formation in Tarim Basin, NW China. These samples are characterized by various barite concretions $(7-18 \mathrm{~cm}$ long) and bands ( $\leq 20 \mathrm{~cm}$ thick), which mainly consist of coarse-grained anhedral to euhedral barite crystals with minor dolomites and pyrites.

Our preliminary results show obvious variation in $\delta^{138 / 134} \mathrm{Ba}$ from $-0.02 \%$ to $0.50 \%$ and the average $\delta^{138 / 134} \mathrm{Ba}$ value is about $0.11 \%$. A roughly positive correlation between $\delta^{138 / 134} \mathrm{Ba}$ and ${ }^{87} \mathrm{Sr} /{ }^{86} \mathrm{Sr}(0.7083$ to 0.7090 ) reveals that $\delta^{138 / 134} \mathrm{Ba}$ can be enhanced by diageneses. The slight variation in ${ }^{87} \mathrm{Sr} /{ }^{86} \mathrm{Sr}$ ratios reveals that the penecontemporaneous seawater may weakly interact with the host fine-grained siliciclastic sediments. The significantly elevated $\delta^{34} \mathrm{~S}$ values (56.8-76.4\% CDT) suggest that the barite may have experienced prolonged strong bacterial sulfate reduction without necessary renewal [2]. If the diagenetic effect is corrected using multiple geochemical parameters, $\mathrm{Ba}$ isotope composition of barite may have great potential for paleooceanographic studies.

[1] McManus et al., GCA, 1998, 62(21), 3453-3473. [2] Zhou et al., PR, 2015, 263, 79-87. 